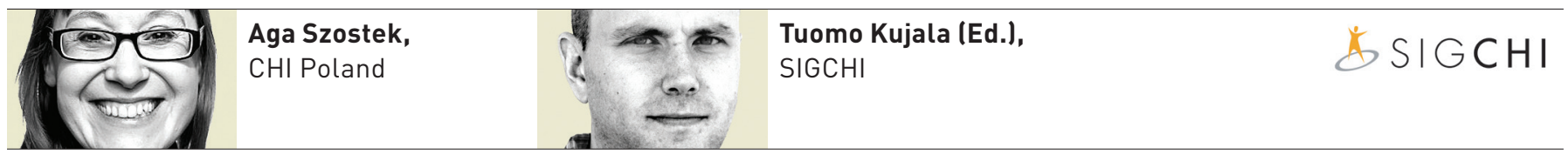

\title{
CHI Poland-
}

A Network of Local Chapters

\section{In CHI Poland, we believe in} empowering people while giving them the freedom to do things their own way. When we started the chapter in November 2010, our group was small and primarily located in Warsaw. Our first event hosted 30 attendees. Our main goal was to establish a network of Polish HCI specialists. Next, we wanted to create a platform for sharing expertise and for mutual support. We also wanted to spread the HCI-related knowledge and to build a basis for promoting HCI values in academia and business. Finally, we strived for expanding the competencies of our members, so they could become pioneers in the field in Poland.

During the first year we organized 10 lectures and became a partner in the Polish Information Architecture Summit, the only usability-related conference in Poland, as well as in the World Usability Day event organized in Katowice. At the end of the year, the lecture hall where we held our events was filled with about 250 guests, who came for talks from Kees Overbeeke from Eindhoven University of Technology and Marcin Brodziak from Google.

With time, other cities indicated their willingness to become active, starting with Kraków, then Wrocław and Poznań. At this point, we were faced with three options: to strive for independent chapters, to consider different associations (UPA, IxDA, etc.), or to consider one umbrellalike organization. There were two problems we foresaw. Poland is a relatively big country, so coordinating sub-chapters, which are spread hundreds of kilometers away, was virtually impossible. We also realized that the people who initiated the local activities wanted to be acknowledged as being the leader of these activities in the place they lived. Therefore, it was crucial to act in a way that made them feel comfortable, while co-running one national organization.

After many discussions, we agreed that our common goal was to build a strong HCI community. We also agreed that this goal needed to reach beyond personal ambitions; however, these ambitions should be realized as much as possible. Based on these premises, we decided to create a network of equal chapters rather than a strong headquarters in Warsaw with satellites in other cities. All leaders had freedom to run their activities in the manner that was most preferred by their local community. At the same time, we agreed to support and to promote each other in every possible way. In the following two years there were more than 40 HCI-related events held all over the country. We also ran the first and the second edition of a survey determining the scope of our community, methods, and tools. We co-organized two subsequent UX conferences and became partners in eight World Usability Day events. Currently, we are preparing the first edition of Polish UX Storytellers, to be published in April.

From an organizational perspective, we are planning to shift the position of the CHI Poland chair from one city and one local chair to another. In this way, every chapter and every leader will have the opportunity to further build our community. This is not an easy solution, but we believe this is probably one of the few ways that enables us to build a single strong community in a relatively large country with a number of differing personal interests.

Needless to say, all our activities are run on a shoestring budget. Polish regulations for associations are construed in a way that involves several costs and bureaucratic procedures for managing a financial flow. We are supported by a number of companies, which are interested in promoting HCI values in Poland, but our own budget is zero. Despite and also because of the limitations in resources, we consider it a great success that we are able to run the Polish chapter in such a way that we can already see the impact we are having. 